\title{
A CONTRIBUIÇÃO E OS LIMITES DA TEORIA DE KLAUS GÜNTHER: A DISTINÇÃO ENTRE DISCURSOS DE JUSTIFICAÇÃO E DISCURSOS DE APLICAÇÃO COMO FUNDAMENTO PARA UMA RECONSTRUÇÃO DA FUNÇÃO JURISDICIONAL
}

\author{
THE CONTRIBUTION AND THE LIMITS OF KLAUS GUNTHER'S THEORY: \\ THE DISTINCTION BETWEEN JUSTIFICATION AND APPLICATION \\ DISCOURSES FOR A RECONSTRUCTION OF JUDICIAL FUNCTION
}

Flávio Quinaud Pedron*

RESUMO: O presente trabalho pretende reconstruir os pressupostos da Teoria da Argumentação Jurídica de Klaus Günther a fim de demonstrar como a separação entre discursos de justificação e discursos de aplicação do direito representa uma resposta mais adequada aos casos de "colisão de princípios" que a teoria de Robert Alexy e demais autores tributários da tradição da Jurisprudência de Valores. Günther ainda desempenha um importante papel na (re) construção de uma teoria processual filiada ao pensamento de Jürgen Habermas (Teoria Discursiva do Direito e da Democracia), demonstrando como é possível a garantia de legitimidade em decisões judiciais mediante a participação das partes processuais como co-autoras da sentença.

PALAVRAS-CHAVE: Aplicação e conflito entre princípio; legitimidade das decisões judiciais; jurisprudência de valores.

* Mestre e doutorando em Direito pela UFMG. Professor de Teoria Geral do Processo e Direito Processual na PUC-Minas. Professor de Hermenêutica Jurídica no Uni-Centro Izabela Hendrix, Belo Horizonte/ MG. Advogado.
ABSTRACT: The following article intends to rebuilt the argumentative base of Klaus Günther's Legal Reasonable in order to demonstrate how the separation between justification and application legal discourses represents a more appropriate answer to cases involving "principles collisions" than Robert Alexy's theory. Furthermore, Günther plays an important role in the (re)construction of a procedural theory related to Jürgen Habermas' discoursive theory, demonstrating how it is possible to achieve legitimacy in the process of adjudication.

KEYWORDS: Aplication and principle's conflict, legal decisions legitimacy, value jurisprudence.

Günther (1993:11), no capítulo de abertura de sua obra principal, Der Sinn für Angemessenheit, esclarece que questões referentes à validade de uma norma devem 
ser separadas das questões referentes à sua aplicação adequada. ${ }^{1}$ Por isso mesmo, o jurista alemão reconstrói e apresenta, por meio de uma separação lógica, uma distinção entre discursos de justificação e discursos de aplicação. No primeiro, tratar-se-ia de perquirir sobre a validade das normas que seriam, posteriormente, aplicáveis prima facie, utilizando-se, para tanto, de um teste de universalização - a partir do princípio do discurso; no outro, pretender-se-ia considerar aquelas normas válidas e, então, diante de um caso concreto especifico, busca encontrar $a$ norma que seja adequada. $\mathrm{O}$ pressuposto aqui é semelhante ao de Dworkin, a unicidade do caso concreto: cada caso é único, assim como cada evento reconstruído no interior de cada processo é singular.

Segundo Günther (1992), se um olhar através da história da Filosofia for lançado, poderá ser percebido que, desde muito, se busca um princípio de universalização, capaz de explicar de maneira suficiente uma troca de papéis entre o agente e a pessoa envolvida na ação buscada. Uma proposta foi a "regra de ouro", a qual exige que no curso do julgamento sobre a ação, o agente se coloque no lugar daqueles que poderão ser atingidos. Outras versões levantam exigências de imparcialidade, de modo que o agente não se

1 "The following section is concerned with the justifications of the thesis that, in moral action, questions of norm validity must be separated from questions of application. [...] it may be sufficient to point out that two distinct activities are involved: on the one hand, justifying a norm by showing that there are reasons, of whatever kind, to accept it, and, the other, relating a norm to a situation by inquiring whether and how it fits the situation, whether there are not other norms which ought to be preferred in this situation, or whether the proposed norm would not have to be changed in view of the situation" (GÜNTHER, 1993:11). deixe dominar por seus próprios interesses, podendo defender publicamente suas ações à luz de razões guiadas por uma "lei universal". Contudo, na compreensão de Wiggins, ${ }^{2}$ lembra Günther, a simples mudança não basta para garantir a justeza moral de uma ação; sua proposta, então, concebe o princípio de universalização a partir de uma análise conjunta de três posições: do agente, do afetado e do espectador. Essa mesma idéia isto é, a busca por critérios que afirmam a possibilidade de se chegar a uma justificação racional moral - parece estar presente na Teoria do discurso; todavia, onde Wiggins fala em "ações", se substitui por "normas" (rever este trecho).

O que se busca, portanto, é uma justificativa geral para uma norma de ação do ponto de vista moral ou jurídico; e, para tanto, Günther apóia-se em Habermas (1987), que já traz uma versão forte desse princípio de universalização na forma do princípio do discurso (D) - "são válidas as normas de ação às quais todos os possíveis atingidos poderiam dar o seu assentimento, na qualidade de participantes de discursos racionais" - que incorpora a crítica de Wiggens, indo além e eliminando qualquer vestígio egocêntrico. ${ }^{3}$ Agora, todos devem

2 WIGGINS, David. Universalizability, impartiality, truth. In: WIGGINS, David. Needs, Values, Truth: essays in the philosophy of value. Oxford: Oxford University Press, 1987.

3 Por isso mesmo, tanto para Habermas (1998) quanto para Günther (1993), normas devem ser observadas a partir da uma racionalidade comunicativa, representando pretensões de validade ligadas à correção de uma ação. Tanto nos discursos de justificação quanto nos discursos de aplicação do Direito e da Moral o princípio discursivo de universalização, em suas respectivas variações - princípio da democracia e 
colocar-se mutuamente na posição do outro e avaliar, de uma maneira conjunta, se a norma corresponde ao interesse universal (GÜNTHER, 1993:23-24; 2000:86). ${ }^{4}$

Günther (1993:23; MORAL SORIANO, 1998:193) reconhece que toda norma acaba por fazer referência a uma situação de aplicação, bem como às conseqüências e efeitos colaterais resultantes de sua aplicação. Se os participantes de um discurso de justificação dispusessem de um conhecimento ilimitado e de tempo infinito, atingiriam uma condição ideal; em decorrência, poderiam prever todas as conseqüências e os efeitos resultantes da observação dessa norma, bem como se o interesse universal foi respeitado (GÜNTHER, 2000:87). Contudo, o próprio autor reconhece que essa pressuposição é irreal; o que não descarta o seu papel contrafactual. Logo,

princípio moral - deve ser observado, preservando a exigência de intersubjetividade e afastando uma justificação/aplicação pautada em uma racionalidade instrumentalizante.

4 "Um acordo a respeito de normas ou ações atingido pelo discurso em condições ideais tem mais do que força autorizadora, ele garante a correção dos juízos morais. A assertibilidade idealmente justificada é o que queremos dizer com validade moral; ela não significa apenas que se tenham esgotado os prós e contras a respeito de um [sic] pretensão de validade controversa, mas ela mesma esgota o sentido da correção normativa como o fato de ser digna de reconhecimento. Diferentemente da pretensão de verdade, que transcende toda justificação, a assertibilidade idealmente justificada de uma norma não aponta além dos limites do discurso para algo que poderia 'existir' independentemente do fato estabelecido de merecer reconhecimento. A imanência à justificação, característica da 'correção', apóia-se num argumento de crítica semântica: porque a 'validade' de uma norma consiste no fato de que ela seria aceita, ou seja, reconhecida como válida sob condições ideais de justificação, a correção é um conceito epistêmico" (HABERMAS, 2004:291, grifos no original).
A tese que pretendo desenvolver é que queremos dizer coisas diferentes quando dizemos que estamos justificando uma norma imparcialmente e quando dizemos que estamos aplicando uma norma a um caso imparcialmente. Se for possível apontar que nosso entendimento pragmático da validade de uma norma não contém sua aplicabilidade a todos os casos, então não precisamos da suposição irrealista (GÜNTHER, 1993:87-88).

É, por isso, que, para toda norma que for aceita como válida a partir de um princípio de universalização, haverá situações nas quais, essa mesma norma, aparentemente, poderá se "chocar" com outra norma igualmente válida, de modo que será possível seguir uma sem descumprir outra. ${ }^{5}$ No campo da moral, temos um exemplo típico: o dever de dizer a verdade pode "conflitar" com o dever de prestar auxílio a uma pessoa necessitada. ${ }^{6}$ Todavia, nem um dever nem

5 Adiantando um pouco a conclusão do presente raciocínio, Bahia lembra que "Günther torna claro que a questão do ‘conflito' entre normas, na verdade é um falso problema. Quando se descobre a norma adequada, percebe-se que as demais permanecem igualmente válidas, apenas que nunca foram cabíveis [isto é adequadas] para aquele caso" (2003:255, grifo no original).

6 Esse exemplo é muitas vezes ilustrado com um fato vivido por Kant: durante uma aula, Kant teria sido interrompido por um aluno que, fugindo de uma perseguição injusta da política do Kaiser, solicita permissão para se esconder debaixo de sua mesa. Kant consente. Todavia, quando a polícia chegar e indagar ao professor se sabe do paradeiro do perseguido, esse informa-lhe que o mesmo está escondido debaixo de sua mesa. Para Kant, o dever de ajudar os necessitados (ainda mais alguém perseguido injustamente) e o dever de dizer a verdade representavam, ambos, máximas universalizáveis à luz do imperativo categórico. $\mathrm{O}$ fato gerou - e ainda gera - longas discussões; por exemplo, ver: Kant, Sobre um pretenso direito de mentir por amor aos homens, e Constant, Das reações políticas (Dos princípios), ambos em REY PUENTE, Fernando (org). Os filósofos e a mentira. Belo Horizonte: Editora UFMG, 2002. (Travessias). 
outro deixam de ser válidos, simplesmente porque irão existir situações em que haja conflito. Por isso, afirma Günther, para a validade de uma norma não se deve considerar uma incompatibilidade empírica.

É, portanto, necessário distinguir duas classes de "colisões".

No primeiro caso, tomando novamente as normas morais como exemplo, tem-se que: a norma que autoriza a quebra de uma promessa, em caso de ganho de vantagem para o promitente, apresenta uma idéia contrária à norma que ordena que uma promessa deve ser cumprida; enquanto a segunda apóia-se em uma pretensão de validade que encontra assentimento universal de todos e, por isso mesmo, pode ser considerada válida, a outra é carecedora dessa mesma condição. Assim, tem-se à frente o que Günther (1995:281) chama de colisão interna, ou seja, aquela que afeta a conclusão sobre a validade de uma determinada norma. Assim, em todas as situações em que a primeira norma for aplicada, teriam sido lesionados os interesses daqueles que confiavam na sua manutenção; essa norma não pode ser válida, uma vez que não satisfaz o teste de universalidade. ${ }^{7}$

Günther explica a necessidade do desenvolvimento de um conceito normativo de coerência - lembrando a concepção de integridade de Dworkin (1999). Assim, coerência aqui é tomada, não apenas como uma exigência de racionalidade, mas de

7 Segundo Günther (1995:281): "Si se muestra que ya, bajo circunstancias que permanecen iguales, en cualquier situación se lesiona un interés común, puede que la norma dudosa no sea válida. En este caso sólo se puede generalizar realmente uno de los dos intereses que colisionan entre sí. El cambio de perspectiva fuerza a los participantes en el discursos a tomar una decisión excluyente (Entweder-Oder-Entscheidung). maneira mais ampla: o ideal de coerência é capaz de conduzir a um sistema de princípios (e de regras, secundariamente) válidos; que, por vez, podem ser identificados por estarem amparados, cada um, a pretensões de validade normativa - no caso, de correção - e por serem produtos de discursos universalizantes, que levam em consideração - como já visto os interesses de todos os sujeitos envolvidos (GÜNTHER, 1995:277). Nessa ótica, encontrarse-iam, no interior desse sistema, apenas as normas válidas produzidas por meio do discurso de justificação. ${ }^{8}$ Todavia, Günther (1995:283) explica que não é possível ordenar essas normas por meio de critérios hierárquicos; todas elas apresentam igual validade. ${ }^{9}$ Mesmo assim, o sistema não está completo, falta uma idéia fundamental: se todas as normas são igualmente válidas e, por isso mesmo, aplicáveis potencialmente a um caso, qual das normas deverá ser aplicada?

8 "O discurso de justificação cuida saber quais normas no ordenamento são válidas (isto é, que protegem adequadamente um interesse universalizável). Segundo o exemplo de Günther [2000:89], quando a aplicação de uma norma sempre signifique a violação de um interesse universalizável, tal norma não é válida (o que seria diferente se a mesma, protegendo um interesse, ocasionalmente ofendesse outro interesse universal). Para o discurso de justificação basta a aferição de validade da norma, isto é, a verificação de que há 'reciprocidade de interesses em circunstâncias constantes' [GÜNTHER, 2000:90; 1992:278]. No discurso de justificação abstrai-se de considerações sobre hipóteses de conflito (aparente) em situações concretas de aplicação. Observa-se no caso hipotético que ambas normas morais representam interesses moralmente universalizáveis, logo, são válidas" (BAHIA, 2004:329, grifos no original).

9 Tal conclusão é contrária à tese sustentada por alguns dos adeptos da tradição da Jurisprudência de Valores; para esses haveria princípios (no caso do Direito) mais importantes que os demais, como o caso do princípio da dignidade humana. 
A pergunta acima remete a um problema diferente e que pode ser ilustrado por outro exemplo moral: a norma que obriga a manutenção de uma promessa é válida da mesma forma que a norma que afirma um dever de auxílio a uma pessoa necessitada; em ambos os casos, fica claro que os interesses são universalizados e estão igualmente apoiados por pretensões sobre a correção normativa. A colisão, então, é considerada como uma colisão externa, que apenas pode ser identificada em situações de aplicação da norma. ${ }^{10}$ Por isso, lembra-se que: não é todo caso de ajuda a um necessitado que demandará a quebra de uma promessa; bem como, nem toda vez que uma promessa for feita, logo em seguida, aparecerá um necessitado precisando de ajuda. E mais, também os necessitados têm interesse de que promessas sejam cumpridas, de modo que a validade da primeira norma permanece inquestionada.

O problema, então, transfere-se para uma esfera do discurso normativo: a aplicação das normas. Em um caso concreto, diversas normas se apresentam como aplicáveis prima facie (GÜNTHER, 1995:283). Todavia, quando as circunstâncias de aplicação dessas normas mostram-se próximas, faz-se necessária uma descrição completa do caso, considerando as

${ }^{10}$ É através da distinção entre colisões internas e colisões externas que Günther (1995:281) pretende pôr em cheque a distinção entre regras e princípios de Alexy, enquanto uma distinção estrutural das normas. O raciocínio de Alexy para as regras, na realidade, referese à colisão interna; todavia esse e a colisão externa acontecem tanto com princípios quanto com regras; e mais, com qualquer outra ordem normativa - por exemplo, a moral. Günther, então, lança mão de um critério procedimental e não materializante (ou semântico), como faz Alexy. circunstâncias individualizantes e sinais característicos em cada situação.

[...] logo ao tomarmos conhecimento de um fato, podemos tomar as normas como somente prima facie aplicáveis. Todo o Direito nos surge como sendo, em princípio, aplicável em sua totalidade de princípios válidos. Todavia, o juízo de adequabilidade perante essas normas válidas é que permitirá aos envolvidos alcançar, com retidão, aquela norma não meramente aplicável prima facie. Da consideração das "normas candidatas" (prima facie aplicáveis) à norma adequada entremeia o discurso que envolve, necessariamente, a reconstrução completa da situação de fato. Disso concluímos que não basta uma descrição "completa" do fático: esta tem que se relacionar com todas as normas aplicáveis, ainda que de maneira virtual-o que leva, também, a uma reconstrução interpretativa e realizativa do Direito (CHAMON JUNIOR, 2004:114, grifos no original).

Um aprofundamento deve ser feito: Günther considera importante distinguir uma descrição de um estado de coisas de uma interpretação de uma situação; a primeira consiste em proposições que podem ser avaliadas como verdadeiras ou falsas, de acordo com a existência de fatos; todavia, se por um lado, a interpretação de uma situação também contém descrições verdadeiras dessa situação, por outro, mostra-se mais abrangente, pois o locutor é responsável por expor em sua interpretação quais descrições verdadeiras do estado de coisas são significativas, e quais não são. Logo, uma interpretação da situação somente pode ser completa se ela contiver todas as descrições do estado de coisas que são simultaneamente verdadeiras e significativas. Todavia, o que se quer dizer com "significativo"? Aqui, o termo é conectado à compreensão que pode ser obtida de uma norma - há uma identidade entre o estado de coisas veiculado no nível da norma e a descrição do caso. 
É, por isso, que a compreensão normativa de coerência do sistema jurídico (ou moral) somente pode ser atingida, levando-se em conta os discursos de aplicação. ${ }^{11}$ Uma vez que as colisões externas são invisíveis quando apartadas de um caso concreto, a coerência normativa somente pode ser estabelecida porque reconstruída - em um estágio final, perante cada caso concreto (CHAMON JUNIOR, 2005:115). Com isso, tanto a exigência de imparcialidade ${ }^{12}$ quanto o ideal da "norma perfeita" - nesse caso, apenas indiretamente foram alcançados (GÜNTHER, 1995:283). ${ }^{13}$

11 "La coherencia a la que se refiere Günther no es un criterio de valoración sino que más bien resume una relación: la que debe existir entre la norma, el resto de normas que prima facie eran aplicables a un caso y, finalmente, la completa descripción de la situación: «Una norma en todas sus variantes semánticas y en relación con otras normas aplicables sea adecuada a la situación descrita completamente». Tanto la adecuación de la norma a una completa situación, cuanto la coherencia de la norma y los aspectos relevantes de una situación, carecen de un contenido material. Más bien resume las relaciones entre la norma y la situación descrita completamente (en el caso de la adecuación) y entre la norma adecuada, el resto de normas aplicables y la situación descrita (en el caso de la coherencia)" (MORAL SORIANO, 1998:202).

12 Segundo Günther, a imparcialidade é agora uma exigência de ordem procedimental, de modo que somente se pode estabelecer a norma aplicável legitimamente ao caso, se são levadas em consideração todas as características relevantes, a partir de uma interpretação coerente de todas as normas aplicáveis. “[...] on ne peut établir qu'un norme peut pégitemement s'apliquer dans une situation que si on été preses en considération toutes les caractéristiques de la situation qui sont relevantes en regard d'une inteprétation cohérente de toutes les normes applicables" (GÜNTHER, 1992:269).

13 “'...] alcançamos o ideal de uma norma perfeita por via indireta: apenas o dividimos em duas etapas distintas. Não antecipamos todas as características de cada situação a um único momento, mas em cada situação, em um determinado momento, todas as suas características. Então, o problema pode ser resolvido pela aceitação de algumas normas como válidas, apesar de sabermos que eles irão colidir com outras normas válidas em alguns casos" (GÜNTHER, 2000:90-91).
Para essa tarefa, lembra Günther (1992:294), os paradigmas são de importância ímpar: ${ }^{14}$ eles determinam certos acentos que são relevantes normativamente em um caso concreto. Os paradigmas, então, reduzem a complexidade da tarefa de redefinição das relações de primazia - e não de preferência entre as normas, de forma que essas são postas em relação dentro de uma ordem transitiva. ${ }^{15}$

Normalmente, nos referimos a uma destas ordens transitivas, quando nos ocupamos com um caso típico de colisão. Estes paradigmas são determinados por uma forma de vida

14 "Un paradigme ccontient une interprétation globale cohérente des normas e des interprátations normatives relatives à certaines descriptions généralisées de situation. L'entrecroisement de la norme et de la description de l'étet de choses s'y situe à un niveau plus général que dans la justifications d'un impératif singuler. L'interpretation globale cohérente est liée à un ensemble déterminé d'interpretations de situation généralisées et collectivement partagées. L'ensemble des interprétations pertinentes est ainsi circonscrit sur la base d'un principe de cohérence interpretative. Pour un ensemble de situations, on affirme que toputes les descriptions de situation signifiants on été prises en considération par un paradigme. Les paradigmes sont liés à des formes de vie. Ils ordonnent un ensemble déterminé de normes intersubjectivement partagées que appartiennent à une form de vie" (GÜNTHER, 1992:294).

15 Como já afirmado em face da teoria de Dworkin, em Günther, os paradigmas também aliviam os participantes de um discurso de aplicação do Direito dos encargos excessivos de racionalização: os paradigmas tornam óbvias certas formas de interpretação e de ver a realidade e a normatividade subjacente (BAHIA, 2004:331). "[A] tentativa de se reduzir a complexidade da interpretação jurídica através da reconstrução de um paradigma jurídico concreto (ou, ainda, da determinação nada isenta de problemas de uma 'ideologia constitucionalmente adotada' ou um 'quadro de valores comum superiores'), que desde o início já estabeleceria um horizonte histórico de sentido para a prática jurídica, só retiraria em parte dos ombros do juiz a tarefa hercúlea de pôr em relação os traços relevantes de uma situação concreta, apreendida de forma a mais completa possível, com todo o conjunto de normas em princípio aplicáveis (CATTONI DE OLIVEIRA, 2002:107-108). 
comum, que é partilhada. Então, por exemplo, toda forma de vida tem sua própria regra de prioridade a respeito da relação entre liberdade e igualdade. Apesar disso, dois aspectos destes paradigmas podem ser criticados por meio do discurso, independentemente de qual seja a forma de vida: a validade das normas singulares, se os interesses vão se alterando e a relação de coerência entre outras normas válidas, se as descrições de situações vão se alterando (GÜNTHER, 2000:97, grifos no original).

As decisões discursivamente tomadas nos processos de aplicação do Direito são para aqui e agora, além de estarem voltadas para um caso determinado e contarem com a participação de sujeitos individualizados. Não há necessidade de empreender a uma reconstrução de toda a história institucional. Todavia, o processo de aplicação deve possibilitar o aporte de interpretações divergentes acerca da interpretação jurídica e da situação concreta (GÜNTHER, 1992:288). A norma adequada será aquela capaz de fornecer uma justificação para um imperativo singular - isto é, o caso concreto único e irrepetível - representando uma maneira de agir, sustentada por uma pretensão de validade referente à correção normativa, na situação in casu (BAHIA, 2004:332).

Pode-se, então, afirmar que há uma divisão de tarefas entre os processos legislativo e jurisdicional, a partir da distinção e correspondências desses processos com os discursos de justificação e aplicação, respectivamente.

Logo, em um discurso de aplicação, o operador do Direito deve pressupor que as normas legisladas são válidas - haja vista elas terem sido positivadas a partir de um discurso de justificação, procedimento esse capaz de garantir, à primeira vista, sua validade. A discussão, portanto, estaria restrita à busca pela norma adequada ao caso concreto. Em um primeiro momento, deve-se proceder a uma justificação interna - ou seja, perquirir um exame semântico dos textos normativos, incluindo referências a precedentes judiciais e considerações teóricas (doutrinárias). Todavia, bem lembra Souza Cruz (2004:225): isso não é suficiente. Como segundo passo, deve-se passar para uma análise dos elementos e aspectos descritivos da realidade fática, de modo a permitir a seleção das características relevantes do caso sub judice. Assim, todas as possibilidades semânticas do texto devem poder cruzar-se com os elementos fáticos do caso - de acordo com um método concretista de aplicação imparcial das normas. Diferentemente, então, do que pensavam os positivistas, "o operador do Direito precisa estar ciente de que mais de uma norma válida pode concorrer prima facie como a mais adequada ao problema" (SOUZA CRUZ, 2004:225-225, grifos no original). ${ }^{16}$

A questão, agora, é determinar um âmbito/grau de restrição à aplicação de uma norma, sem, com isso, questionar a sua validade - regredindo a um discurso de justificação como, por exemplo, faz a ponderação de princípios.

Mas, então, cabe uma questão: como fica a noção de "segurança jurídica", tão cara para os positivistas? Habermas (1998:291) responde

16 "No processo de aplicação, seleciona-se, em meio às normas [justificadas] que apenas se candidatam para um caso dado, aquela que é cada vez [adequada]. Aqui se manifesta a descoberta hermenêutica de que a norma apropriada é concretizada à luz das características da situação dada e, que, inversamente, o caso é descrito à luz das determinações normativas pertinentes" (HABERMAS, 2004:277). 
afirmando que a única saída dá-se pela reconstrução do conceito. Uma vez que o "modelo de regras" foi completamente ultrapassado, a "nova" leitura assenta-se na base da função do Direito - qual seja, a garantia de expectativas de comportamento-entretanto, o que aqui representa previsibilidade deve estar aberto para a dupla dimensão da tensão entre facticidade e validade.

A proposta positivista virava as costas para essa última dimensão, diluindo decisões institucionais sob uma facticidade, todavia, questionável. Logo, a proposta discursiva transfere o conceito de "segurança" para a garantia dos direitos processuais; aqui, todos os cidadãos deverão ter garantida a sua participação, além de que todas as questões fático-jurídicas pertinentes sejam ventiladas e debatidas. A "segurança", portanto, migra da previsibilidade de resultado para a garantia de direitos participatórios nos processos de tomada de decisão estatal.

Conclui, então, Souza Cruz (2004:237) que a decisão adequada - ou a resposta correta, como quer Dworkin - não se encontra sob a base de um consenso ético-substantivo majoritário; ela está no procedimento que levanta exigência de observância dos princípios informadores do devido processo constitucional, de uma reciprocidade entre participantes e do "discurso jurídico", que conjuntamente podem realizar uma filtragem dos direitos fundamentais.

Todavia, Günther (1992:298) construiu sua tese a partir de uma compreensão do Direito como caso especial do discurso moral; isso porque os discursos jurídicos, apesar de particularidades ante os discursos morais, ainda guardariam muitas similitudes - a principal é a de que normas jurídicas poderiam ser justificadas moralmente; vindo a ser muito criticado por Habermas (1998:304).

Importante, então, ter em mente a tese de Alexy (2001; 1998), que sustenta que a correção de uma decisão judicial é sempre relativa, haja vista a impossibilidade de haver uma legislação isenta de colisões entre normas, principalmente no tocante aos princípios (em sua leitura, valores).

Mas, em Habermas, é possível extrair legitimidade da legalidade (SOUZA CRUZ, 2004:227), tornando autônomo o discurso jurídico na sua relação com a moral. Diversas, então, são as razões para a crítica da tese do caso especial: ${ }^{17}$

${ }^{17}$ Interessante a análise a que procede Atienza (2002:288-289, grifos no original): "A tese central da teoria de Alexy [...] consiste em afirmar que a argumentação jurídica - o discurso jurídico - é um caso especial do discurso prático geral. A essa tese pode-se dirigir tanto uma crítica conceitual quanto uma crítica centrada no alcance prático da teoria ou, então, em seu significado ideológico. [...] Do ponto de vista conceitual, a primeira crítica que se pode fazer à tese do caso especial é que ela é ambígua e por partida dobrada. Uma primeira ambigüidade deriva do fato de a ênfase de que o discurso jurídico seja um caso do discurso prático geral, o que destaca o caráter racional da argumentação jurídica, sua proximidade em relação ao discurso moral, ou então no fato de que se trata de um caso especial, o que ressalta as deficiências de racionalidade do discurso jurídico [...]. O segundo tipo de ambigüidade consiste [...] na falta de clareza quanto ao que Alexy entende por argumentação jurídica ou discurso jurídico: em sentido estrito, o discurso jurídico seria um procedimento nãoinstitucionalizado que se situa entre o procedimento de estabelecimento estatal do Direito e o processo judicial; em sentido amplo, também se argumenta juridicamente no contexto desses últimos procedimentos, embora Alexy reconheça que, neles, não só é questão de argumentar como também de decidir. E aqui, a propósito do que chamei de 'discurso jurídico em sentido estrito' (e que Alexy chama de 'discurso jurídico como tal' [2001]), surge, de novo, uma certa ambigüidade. Por um lado Alexy indica que esse - o discurso jurídico como tal - é um tipo de procedimento não-institucionalizado (para ele isso significa - é preciso lembrar - que não está 
(1) na argumentação jurídica, diferentemente da moral, as partes não estão obrigadas a proceder a uma busca cooperada pela verdade; o Direito abre espaço para ações estratégicas que possam conduzir a uma decisão favorável. Mesmo assim, em razão do elevado grau de racionalidade presente no processo, pode-se atingir um juízo de aplicação imparcial (SOUZA CRUZ, 2004:228);

(2) com isso, são apagadas as linhas fundamentais da diferenciação entre discursos de justificação e discursos de aplicação - o melhor exemplo é a técnica de ponderação de Alexy. Nos discursos de aplicação, pesa a limitação da argumentação mais ampla existente nos discursos de justificação - argumentos pragmáticos e ético-políticos devem ficar excluídos, sob pena de se aceitar uma reabertura do processo legislativo, todavia, com um rol de legitimados à discussão muito inferior. Com isso, não se quer negar que, ao longo de um discurso de aplicação jurídico, não surjam questões políticas e pragmáticas; alerta-se para o fato de que a decisão não poderá reabrir a discussão de justificação, ou seja, o magistrado deve tomá-las como produto do discurso anterior e tratá-las

regulado por normas jurídicas que assegurem a chegada a um resultado definitivo e que seja, além disso, obrigatório, o que faz pensar que com isso ele está se referindo basicamente à argumentação da dogmática jurídica). Mas, por outro lado, quando Alexy contrapõe o 'discurso jurídico como tal' ao discurso no processo judicial [...], ele inclui, nesse último item, as argumentações que as partes do processo empreendem, ao passo que a argumentação levada a efeito pelo juiz pertenceria ao primeiro contexto (que - lembre-se - ele havia caracterizado como 'não-institucional'). como válidas prima facie, avaliando-as e posicionando-se apenas no tocante à adequabilidade delas perante as circunstâncias do caso concreto, sem, com isso, buscar construir novos argumentos de ordem pragmática ou ético-política; ${ }^{18} \mathrm{e}$

(3) Habermas (1998:305) ainda lembra que a legitimidade das normas jurídicas não pode ser medida pelo "critério de universalização de interesses" de Günther, mas somente pela racionalidade inerente ao processo legislativo.

Esse segundo ponto é justamente um problema que transparece na tese de Alexy sobre a técnica da ponderação. Habermas irá criticar principalmente a ausência de uma racionalidade (discursiva) capaz de legitimar a decisão. Todavia, mesmo em artigos recentes, Alexy (2005:573) ainda não parece ou não quer - compreender bem esse ponto; em sua réplica, esclarece que a ponderação parte de uma estrutura complexa de subregras e busca atingir um resultado que encontra respaldo, até mesmo, em uma fórmula matemática. ${ }^{19}$

18 "No controle de constitucionalidade das leis, o Judiciário deixa de aplicar uma norma ordinária, válida prima facie, para aplicar diretamente a norma constitucional ao caso concreto" (SOUZA CRUZ, 2004:230).

19 Segundo Alexy (2005:575-576): "The simplest form of the Weight Formula goes as follows: $W_{i, j}=I_{i}$ $I$. Let Ii stand for the intensity of interference with the principle $\mathrm{Pi}$, for example, the principle granting the freedom of expression of Titanic. Let $\mathrm{Ij}$ stand for the importance of satisfying the competing principle $\mathrm{Pj}$ - in our case, the principle granting the personality right of the paraplegic officer. And let Wi,j stand for the concrete weight of Pi. The Weight Formula makes the point that the concrete weight of a principle is a 
Tal resposta apenas reforça a crítica habermasiana: a racionalidade matemática é típica de uma busca pela verdade de uma afirmação e difere-se, radicalmente, de um juízo sobre a correção de uma ação (HABERMAS, 2004). A principal diferença decorre do fato de o juízo sobre a verdade seguir correspondência com um mundo objetivo, completamente diverso do mundo intersubjetivo, ${ }^{20}$ no qual se situam as normas. Naquele a relação se dá entre sujeitos e objetos e, por isso, pesa uma racionalidade de tipo instrumental, enquanto no segundo, tem-se uma relação entre sujeitos e, por isso mesmo, apoiada por uma racionalidade de tipo comunicativo. Ao transpor essa lógica instrumental para o universo normativo, conclui Habermas, abre-se para o aplicador um espaço de subjetividade (discricionariedade), desligando-o do dever de apresentar razões capazes de encontrar assentimento racional nos demais membros da sociedade. A fixação de meio e fins é tarefa que cabe aos co-participes do processo legislativo, não aos aplicadores jurídicos. ${ }^{21}$

relative weight. It does this by making the concrete weight the quotient of the intensity of interference with this principle (Pi) and the concrete importance of the competing principle $(\mathrm{Pj})$ ".

20 "Diferentemente da pretensão de verdade, que transcende toda justificação, a assertabilidade idealmente justificada de uma norma não aponta além dos limites do discurso para algo que poderia 'existir' independentemente do fato estabelecido de merecer reconhecimento. Aimanência à justificação, característica da 'correção', apóia-se num argumento de crítica semântica: porque a 'validade' de uma norma consiste no fato de que ela seria aceita, ou seja, reconhecida como válida sob condições ideais de justificação, a correção é um conceito epistêmico" (HABERMAS, 2004: 291).

21 "Em síntese, confere-se mais uma vez poderes discricionários ao Judiciário, no sentido de colocar-se na 'pele' do legislador político e verificar se, a seu juízo,
No caso dos adeptos da "jurisprudência de valores", a tentativa por relativizar a Constituição, bem como sua supremacia, lendo-a conforme uma ordem concreta de valores, compromete a própria idéia de Constituição: uma vez que essa é a fonte do código de funcionamento do Direito, código esse apoiado em uma lógica binária que separa o lícito (constitucional) do ilícito (inconstitucional). Decisões não apoiadas nesse código são, conseqüentemente, decisões desprovidas de razões jurídicas. Retorna aqui o problema já apresentado sobre as complicações que podem advir de uma equiparação de normas à valores. ${ }^{22}$

haveria uma medida que fosse melhor. Esse elemento impõe um decisionismo absoluto, na medida em que propõe ao Judiciário o papel de definição das diretrizes políticas e de argumentos pragmáticos" (SOUZA CRUZ, 2004:240).

${ }^{22}$ Para que isso fique claro, pode-se partir do raciocínio seguinte. Normas, segundo Habermas (1998:328, 2004:291), são justificadas a partir de uma pretensão de correção (referência ao justo), devendo poder contar com a aceitação racional daqueles que serão seus afetados (1998:172). Dessa forma, diante de uma pretensão normativa, os atores sociais podem tomar dois caminhos diversos: concordarem mutuamente sobre as pretensões de validade de seus atos de linguagem, ou levantarem pontos em que haja discordância, problematizando-os. Instala-se assim a possibilidade de avaliação através de uma ação comunicativa. As discordâncias advindas dessa forma de ação podem ser solucionadas a partir do uso de razões (argumentos) capazes de convencer ambos os lados (HABERMAS, 2004:295). Contudo, o que se percebe é que o consenso sobre normas apresenta um outro lado importante. Através do Princípio U (Princípio de Universalização), os participantes voltam-se para a possibilidade de universalização das normas de ação capazes de transcender contextos culturais específicos e, com isso, adquirir validade para todos os seus destinatários de maneira igual, ou seja, sem exceções. Diferentemente das normas, uma concepção ética - ligada ao que seja o bem - não apresenta esse potencial de universalização contido nos discursos sobre a correção das normas, uma 
A Teoria do Discurso, então, permite repensar a dinâmica da atividade jurisdicional, sempre pressupondo a dimensão democrática. Torna-se importante distinguir bem dois modelos apresentados por Günther (1995:37): ${ }^{23}$ (1) o modelo da correia de transmissão, segundo o qual o juiz deve aplicar o Direito que é elaborado anteriormente por um legislador democrático. A legitimidade da decisão, então, decorre da observância à legalidade, ou seja, ao Direito pré-fixado nos processos de legislação; e (2) o modelo do bilhar, que afirma que a atividade de aplicação jurídica tem legitimidade por si mesma, independentemente da existência do legislador. Aqui a aplicação do Direito e a legislação, às vezes, correm em sentido paralelo, e até mesmo contrário. ${ }^{24}$ Uma vez

vez que se encontra enraizada sob valores pré-reflexivos, isto é, concepções culturais partilhadas intersubjetivamente por uma determinada forma de vida concreta. Por isso, a noção de bem liga-se à idéia de um nós, uma comunidade determinada assentada sob uma mesma concepção de vida boa. Desse modo, as referências para as ações oriundas dessa comunidade apenas podem ser compreendidas como respostas a fins específicos (caráter instrumental) julgados a partir das preferências comuns de seus membros. Logo, apenas uma concepção normativa (deontológica) é capaz de satisfatoriamente apresentar respostas à solução de controvérsias práticas, porque, no procedimento de justificação de normas, acontece um discurso argumentativo, pautado em pretensões de validade que retiram os falantes do contexto em que se encontram enraizados, de modo que posições e preferências pessoais sejam analisadas e criticadas a partir de uma perspectiva intersubjetiva abrangente.

23 Como lembra Günther (1995:38), trata-se de modelos ideais, que não necessariamente apresentam todas as suas características na prática social.

24 "The law which is made by the legislator and the law which is made by the judge are like billiard balls, rolling in different directions or bouncing off each other. They can roll in the same direction, but they do not necessarily do so. In most cases, the law given by the que o Direito legislado é permeado por indeterminações, ou mesmo incapaz de exprimir o "verdadeiro" Direito pelo qual o povo anseia - principalmente em razão de o processo legislativo poder ser regido pelo sabor das forças políticas, os magistrados vêem-se forçados a adaptar o que foi positividado, podendo até mesmo criar novos direitos. Para esse modelo, caso os juízes não estejam representando bem a vontade popular, sempre há espaço para que os legisladores interfiram, produzindo novas leis, mudando o curso das decisões futuras. Todavia, adverte Günther (1995:37), o círculo vicioso se reinstala, podendo o Judiciário compreender diferentemente a mensagem provinda do Legislativo. ${ }^{25}$ A validade jurídica, então, encontra-se fracionada: em parte, deriva dos processos de legislação, mas também decorre das decisões proferidas pelo Judiciário.

Acontece que nem um nem outro modelo são referências adequadas aos processos de

legislator is like a message from another planet, its meaning is indeterminate, many terms are vague, and the circumstances under which it is made change rapidly. This has to do with the fact that often the law is not made by the people for the people, but is the result of a compromise between political groups struggling for power. The judge has to reconstruct the law, has to adapt it to changed circumstances, and, in some cases, or in every case, she invents the law, generates a new meaning. Law is indeterminate, so the judges invent new general rules which have a curtain binding force for others judges" (GÜNTHER, 1995:37).

25 "To be sure, the billiard ball model concedes that the democratic legislator can always intervene in the judge-made law in order to change it for the adjudication of future cases. In this way, the legislator retains an institutional supremacy over adjudication. But then, it's the same old story: the intervention of the legislator is only a new message from another planet, and the judges will again have to interpret the new law according to their own rules" (GÜNTHER, 1995:37). 
aplicação do Direito democrático. O primeiro caso ainda está preso à noção de "vontade geral" de Rousseau, ao passo que o segundo lança similitudes com o realismo jurídico. A bem da verdade, ambos deixam de observar um problema importante: a questão da aplicação particular (GÜNTHER, 1995:43).

Um procedimento imparcial de aplicação do Direito, então, deve levantar exigências de iguais considerações de todas as particularidades apresentadas pelo caso. Desta sorte, uma aplicação imparcial de uma norma significa compreendê-la como a norma adequada capaz de, simultaneamente, ser interpretada como se fizesse parte de um sistema coerente de normas e fornecer uma resposta para o caso particular, preenchendo uma exigência de correção normativa para aquela ação singular.

Nesse caso, a proposta, então, passa não por adotar um dos dois modelos apresentados mas por lançar um olhar reconstrutivo para um novo - que, todavia, encontra no modelo da correia de transmissão o seu ponto de partida. Esse novo modelo, bem mais satisfatório, decorre das pesquisas habermasianas (GÜNTHER, 1995:46). A mudança principal decorre do fato de os discursos jurídicos institucionalizados interpretarem - e aqui, um alerta: Habermas e Günther tomam o conceito de interpretação conforme a noção gadameriana; assim, interpretar é, simultaneamente, compreender e aplicar - todo o direito à luz do sistema de direitos, já que esse é o núcleo tanto da atividade de legislação democrática quanto da atividade de aplicação jurídica. ${ }^{26}$ Como

26 "To be sure, the system of rights is not given in advance as an independent code which has only to be conseqüência, as respostas funcionais dessas atividades estão, ambas, conectadas à forma do Direito - garantia de liberdade individual (autonomia privada) e de igual consideração (autonomia pública) (GÜNTHER, 1995:46).

Por meio dos discursos de justificação, o legislador político avalia um espectro ilimitado de razões de normativas e pragmáticas, traduzindo-as à luz do código do Direito. O aplicador jurídico, por outro lado, encontra uma constelação de normas bem mais limitadas - ele apenas pode lançar mão das escolhas já feitas pelo legislador. Além disso, todas as escolhas do legislador, uma vez traduzidas conforme o código do Direito, agora funcionam sob a lógica jurídica; por isso mesmo, a tarefa deixada a cargo do aplicador não é mais de justificar tais razões, mas de encontrar, dentre as que o legislador considerou como prima facie válidas, a adequada para fornecer uma fundamentação acerca da correção da ação singular trazida pelo caso sub judice.

Assim, é o caso concreto - mediante suas particularidades - que vai fornecer o espectro de normas a serem examinadas. A noção de aplicação imparcial aqui é entendida como uma exigência de que o procedimento de aplicação leve em conta a participação daqueles que são os destinatários da norma a ser aplicada. Logo, lembra Günther (1995:50),

\footnotetext{
applied by legislation. It does not represent God's point of view, as He gave the law to Moses. Instead, it is something like an idealized internal reference point for the members of a society who conceive of themselves as authors and addressees of equal rights. As such an idealizes internal reference point, the system of rights functions like a generative grammar for the language in which the members of a legally institutionalized rational discourse express their particular opinions for and against a suggested law" (GÜNTHER, 1995:47).
} 
tanto as partes quanto o juiz são partícipes dessa dinâmica; todavia, eles desempenham papéis diferentes, mas nem por isso menos importantes. O juiz, então, desempenha um papel de terceiro observador do conflito: cabe a ele questionar sobre a coerência das interpretações levantadas pelos participantes (autor e réu) quanto ao caso, bem como quanto à norma adequada. Dessa forma, a decisão não é apenas sua mas uma construção conjunta que deve ainda se voltar para a sociedade - uma vez que a mesma é a real titular (e atingida) pelo sistema coerente de normas válidas, representado pelo Direito. Uma decisão pode ser considerada fundamentada quando, além de demonstrar a reconstrução argumentativa dos acontecimentos relevantes do caso concreto, explicita a norma adequada a servir de justificativa para a ação singular. Essa decisão, então, não é apenas dirigida aos litigantes, mas a toda a sociedade. ${ }^{27}$

${ }^{27}$ Em recente trabalho, Alexy (2005:578) busca justificar a legitimidade de uma Corte Constitucional, não em razão da potencial participação e aceitação racional da sociedade, mas a partir do que ele considera uma representação argumentativa: "The representation of the people by a constitutional court is, in contrast, purely argumentative. The fact that representation by parliament is volitional as well as discursive shows that representation and argumentation are not incompatible. On the contrary, an adequate concept of representation must refer-as Leibholz puts it—-to some 'ideal values'. Representation is more than-as Kelsen proposes-a proxy, and more than-as Carl Schmitt maintainsrendering the repraesentandum existent. To be sure, it includes elements of both, that is, representation is necessarily normative as well as real, but these elements do not exhaust this concept. Representation necessarily lays claim to correctness. Therefore, a fully-fledged concept of representation must include an ideal dimension, which connects decision with discourse. Representation is thus defined by the connection of normative, factual, and ideal dimensions" (2005:579, grifos no original). Nesse sentido, o déficit de legitimidade das Cortes Constitucionais poderia ser
Uma vez que os litigantes detêm espaço para agir estrategicamente, seu assentimento não é necessário para que decorra a obrigatoriedade natural do provimento (GÜNTHER, 1995:50); a legitimidade da decisão está preservada se for garantido aos mesmos a oportunidade de se manifestarem - isto é, o princípio do contraditório - de modo a poderem reconhecer-se como coautores desse provimento. Por isso mesmo, o conflito entre litigantes, à luz da Teoria do Discurso, aparece de modo diferente: um conflito jurídico emerge como uma disputa particular entre dois (ou mais) sujeitos de direito, que questionam o significado das razoes jurídicas que podem ser aceitas pelos participantes de um discurso público (GÜNTHER, 1995:52).

Todavia, a possibilidade de alternância entre os papéis de autor e destinatário das normas vê-se bloqueado: paras partes que não podem entender-se, exclusivamente, como autores das normas, já que, da discussão, estão excluídos os demais cidadãos, bem como, por força da ação estratégica, submeterse-ia a "vontade geral" à vontade particular; nem para o juiz, já que o discurso de aplicação impede o retorno às razões que levaram a justificação da norma.

O principal, então, será realizar o desbloqueio por meio da troca interpretativa entre as partes, lembrando-as de seu papel como participantes iguais dos discursos públicos. Transcendendo o particularismo do caso sub judice, a decisão, para considerar-se

\footnotetext{
superado pela existência de pessoas capazes de avaliar as pretensões de validade de correção das normas. O que é bem diverso de Habermas, para quem a racionalidade não está nos sujeitos, mas no procedimento de tomada de decisão.
} 
fundamentada, deve ainda se pautar em razões jurídicas que poderiam ser aceitas racionalmente pela sociedade. Günther (1995:52), então, reconhece que a opinião pública adquire um papel importante no paradigma procedimental do Estado Democrático de Direito.

A crítica pública à decisão, permanentemente, lembra aos aplicadores do Direito (conceito esse compreendido em sentido amplo e não apenas relacionado aos magistrados) que são meros representantes do papel que desempenham na aplicação do Direito. É, por isso, que Günther (1995:53) afirma que a interpretação jurídica não pode ser assumida como uma questão de escolha ou opção pessoal do aplicador, mas sim ligada a um esquema coerente de princípios de justiça, de igualdade e de liberdade amparado por razões de natureza pública compartilhadas pela sociedade.

\section{REFERÊNCIAS}

ALEXY, Robert. Balancing, constitutional review, and representation. International Journal of constitutional Law. Oxford University Press e New York University School of Law, 2005. v. 3. n. 4.

ALEXY, Robert. Teoria da Argumentação Jurídica: a Teoria do Discurso Racional como Teoria da Justificação Jurídica. Trad. Zilda Hutchinson Schild Silva. São Paulo: Landy, 2001.

ALEXY, Robert. Derecho y Razón Práctica. 2. ed. México: Fontamara, 1998.

ATIENZA, Manuel. As razões do direito: teorias da argumentação jurídica. 2.ed. Trad. Maria Cristina Guimarães Cupertino. São Paulo: Landy, 2002.

BAHIA, Alexandre Gustavo Melo Franco. A interpretação jurídica no Estado Democrático de Direito: contribuição a partir da Teoria do
Discurso de Jürgen Habermas. In: CATTONI DE OLIVEIRA, Marcelo Andrade (Coord.). Jurisdição e Hermenêutica Constitucional no Estado Democrático de Direito. Belo Horizonte: Mandamentos, 2004.

BAHIA, Alexandre Gustavo Melo Franco. Controle judicial difuso de constitucionalidade das leis e atos normativos: contribuição para a construção de uma democracia cidadã no Brasil. 2003. Dissertação (Mestrado em Direito Constitucional) - Faculdade de Direito, Universidade Federal de Minas Gerais, Belo Horizonte.

CATTONI DE OLIVEIRA, Marcelo Andrade. Direito Constitucional. Belo Horizonte: Mandamentos, 2002.

CHAMON JUNIOR, Lúcio Antônio. Filosofia do Direito na Alta Modernidade: incursões teóricas em Kelsen, Luhmann e Habermas. Rio de Janeiro: Lumen Juris, 2005.

CHAMON JUNIOR, Lúcio Antônio. "Tertium non datur": pretensões de coercibilidade e validade em face de uma teoria da argumentação jurídica no marco de uma compreensão procedimental do Estado Democrático de Direito. In: CATTONI DE OLIVEIRA, Marcelo Andrade (Coord.). Jurisdição e Hermenêutica Constitucional no Estado Democrático de Direito. Belo Horizonte: Mandamentos, 2004.

DWORKIN, Ronald. O Império do Direito. Trad. Jefferson Luiz Camargo. São Paulo: Martins Fontes, 1999. (Coleção Direito e Justiça).

GÜNTHER, Klaus. Uma concepção normativa de coerência para uma teoria discursiva da argumentação jurídica. Trad. Leonel Cesarino Pessoa. Cadernos de Filosofia Alemã. São Paulo. n. 6. a. 2000.

GÜNTHER, Klaus. Legal adjudication and democracy: some remarks on Dworkin and Habermas. European Journal of Philosophy. Essex: Blackwell Publishers. v. 3. n. 1. abr./1995. GÜNTHER, Klaus. Un concepto normativo de coherencia para una teoría de la argumentación jurídica. Trad. Juan Carlos Velasco Arroyo. Doxa. n. 17-18. a. 1995b. 
GÜNTHER, Klaus. The sense of appropriateness: application discourses in morality and law. Trad. John Farrell. New York: State University of New York, 1993.

GÜNTHER, Klaus. Justification et application universalistes de la norme en droit et en morale. Trad. Hervé Pourtois. Archives de Philosophie du Droit. Sirey, t. 37. a. 1992.

HABERMAS, Jürgen. Verdade e Justificação: ensaios filosóficos. Trad. Milton Camargo Mota. São Paulo: Loyola, 2004. (Humanística).

HABERMAS, Jürgen. Facticidad y Validez: sobre el derecho y el Estado democrático de derecho en términos de teoría del discurso. Trad. Manuel Jiménez Redondo. Madrid: Trotta, 1998.
HABERMAS, Jürgen. Teoría de la acción comunicativa. Trad. Manuel Jiménez Redondo. Madrid: Taurus, 1987. 2 v. (Tomo I: Racionalidad de la acción y racionalización social; Tomo II: Crítica de la razón funcionalista).

MORAL SORIANO, Leonor M. ¿Qué discurso para la moral? Sobre la distinción entre aplicaron y justificación en la teoría del discurso práctico general. Doxa. n. 21. t. 1. a. 1998.

REY PUENTE, Fernando (Org.). Os filósofos e a mentira. Belo Horizonte: Editora UFMG, 2002. (Travessias).

SOUZA CRUZ, Álvaro Ricardo de. Jurisdição constitucional democrática. Belo Horizonte: Del Rey, 2004. 